\title{
Assessing the Relationship among the Land Surface Features: A Geographic Information System (GIS) and Remote Sensing (RS) Based Approach for City Area
}

\author{
Sharmin Siddika ${ }^{\mathrm{a}}$, Md. Nazmul Haque ${ }^{\mathrm{a},{ }^{*}}$ and Mizbah Ahmed Sresto ${ }^{\mathrm{a}}$ \\ ${ }^{a}$ Department of Urban and Regional Planning, Khulna University of Engineering \& \\ Technology, Khulna- 9203, Bangladesh
}

\begin{abstract}
Due to climate change and urbanization, it is important to monitor and evaluate the components of the environment. For this reason, ward-22 and ward-27 of the Khulna City Corporation (KCC) area have been selected for the study. This research seeks to identify the existing land use profile and assess the land surface components such as topography, Normalized Difference Buildup Index (NDBI), Normalized Difference Vegetation Index (NDVI), Normalized Difference Moisture Index (NDMI), Normalized Difference Salinity Index (NDSI) and Land Surface Temperature (LST) to measure the relationships among the land surface components. The land use land cover map shows that about $59 \%$ of ward-22 and $71.5 \%$ area of ward-27 are built-up areas. Both of the wards contain little amount of water body, vegetation and open space. Both of the wards have residential land use types with commercial purposes on the periphery. Accordingly, $63.32 \%$ and $65 \%$ of structures of ward-22 and 27 are pucca. The land surface components reveal that both areas contain lower slopes, less vegetation, less moisture, severe salinity, highly built-up areas, and high land surface temperature. The relationships among the land surface components show that NDVI has a negative relation with LST and NDBI whereas NDVI represents a positive correlation with NDMI. On the other hand, NDBI shows a positive correlation with LST whereas NDMI negatively correlates with LST. NDSI and topography reflect no meaningful relationship between NDBI, NDVI, LST, and NDMI. However, the research findings may be essential to city planners and decision-makers for incorporating better urban management at the micro level concerning climate change.
\end{abstract}

Keywords: Environment, Land use land cover, Land Surface Features, Remote Sensing.

\section{Introduction}

Environmental change made by mankind's exploitation, as well as regional climate changes, have long been a serious problem around the world, particularly in coastal regions due to the susceptibility of their ecosystems [1-3]. Due to urbanization and industrialization, substantial environmental and ecological changes have occurred over the last century, particularly in the last 20 years, raising societal concerns [4]. Land transformation is an important issue in understanding the interaction between humans and the environment since it is driven by both natural and anthropogenic driving forces [5]. The widespread urbanization has harmful repercussions on the Earth's surface,

\footnotetext{
* Corresponding author. Tel.: +8801681934283

E-mail address: nhaque13@urp.kuet.ac.bd; nhaque.kuet13@gmail.com

Manuscript History:

Received 6 July, 2021, Revised 17 September, 2021, Accepted 19 September, 2021, Published 31 October, 2021

Copyright (C) 2021 UNIMAS Publisher. This is an open access article under the CC BY-NC-SA 4.0 license.

https://doi.org/10.33736/jaspe.3616.2021
}

e-ISSN: 2289-7771

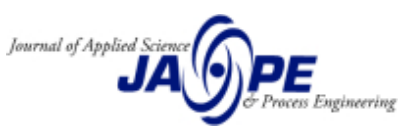


resulting in significant environmental changes [6-7]. Change in urban land use has been one of the most dramatic land conversion processes that have been extensively investigated [8]. Urban ecosystem assessment is vital for town planners and other stakeholders because of various implications of the increase in urban land cover [9].

Increasing built-up area results in broad land use and land cover change, with negative implications on multiple environmental indices, namely NDSI, NDVI, NDBI, NDMI and LST [10]. Such practices are ultimately unsustainable, resulting in a reduction in a region's overall environmental health. Several methods have been used to evaluate the various environmental implications of LULC, including remote sensing assessments of surface changes utilizing, for example, LST, NDVI, and NDBI. [5, 11-12]. LST was frequently used in global temperature change research studies, as well as hydrological, geo-biophysical, and LULC studies [13]. Remote sensing images that are multi-temporal can generate essential data for successfully assessing spatial urban information and the thermal environment [14]. Previous research had found a strong negative association between LST and NDVI, despite the fact that NDVI varies considerably with season [15]. The Normalized Difference Vegetation Index (NDVI) and the Normalized Difference Built-Up Index (NDBI) had been employed as indicators for vegetation cover and amount of urbanization respectively [16]. Land surface temperature (LST) was intimately related to and impacted by other biophysical factors such as normalized difference vegetation index (NDVI), normalized difference built-up index (NDBI), and normalized difference water index (NDWI) [17]. Several studies have looked at the relationship between normalized difference vegetation index, land surface temperature and land use/land cover connections [18].

Bangladesh faces a number of serious environmental issues, including air pollution, surface water pollution, solid waste problems, and noise pollution [19]. Although the population has grown dramatically, infrastructure development has been so slow that a number of serious problems have arisen as a result of population growth, slum expansion, and illegal migration [20]. A developing country like Bangladesh is going through a major change in urbanization and civilization. Acres of agricultural land is turning into built areas and thus the extension of the city is expanding day by day [21]. Dhaka, Bangladesh's capital, has lost 75 percent of its wetlands in the last few decades caused by rapid urbanization and industrialization. This unplanned growth has an impact on both large and small cities [22]. A port city like Khulna is also not out of its influence. Industrialization and transportation are increasing under the pressure of expanding population. As a planner, it is essential to determine the environmental profile for developing short- and long-term plans for land use in urban and rural areas while balancing considerations such as social, economic, and environmental issues. In this paper, the environmental profile and the characteristics of land surface components of ward-22 and ward-27 of Khulna city are studied. It should be mentioned that there have been no other studies on this small scale of area (ward-22 and ward-27). Evaluating the surface indices is crucial for such small-scale areas because it provides insights into the micro climatic condition. Calculation of the different biophysical parameters will help to assess overall environmental issues in ward-27 and ward22 due to the increase in urban sprawl. Monitoring of land surface components is important on a regional scale but smaller scale monitoring and assessment are essential for land use planning and sustainable environmental management.

The main objective of this study was to identify the existing land use profile and assessment on the components/ biophysical parameters (NDVI, NDMI, NDSI, NDBI and LST) of a land surface. The study also focused on evaluating the correlation between several land surface components and their effects on the study area. The identification of the land use profile and the related indices would provide a visual representation of the study area in a microclimatic context. On the other hand, an assessment of the relationships would provide an insight into how the indices/components were related to each other and how one component was influencing the other.

Although there were some limitations while conducting the overall study, the study area was comparatively small so the variation in land surface classification was not quite substantial. Most of 
the data were collected based on secondary data sources as it was difficult to conduct field surveys more than once due to the ongoing pandemic situation.

\section{Methodology}

\subsection{Study area}

The selected area for this research was ward-22 and ward-27 of Khulna City Corporation (KCC) (Figure 1). These two wards are under Kotwali Thana. They are situated near the Bhairab River. Both of the wards are located in the old part of KCC and are considered as unplanned built-up areas. Ward22 is bounded by Bhairab River on the east side, Rupsha stand road on the south side and Hadis Park is on the west side of the ward. Similarly, ward-27 is bounded by Khan Jahan Ali road on the north, Sher-E-Bangla road on the west and Upper Jashore road on the east [23]. Ward-22 has a total land area of 0.68 square kilometres whereas ward-27 has an area of 0.82 square kilometres [12].

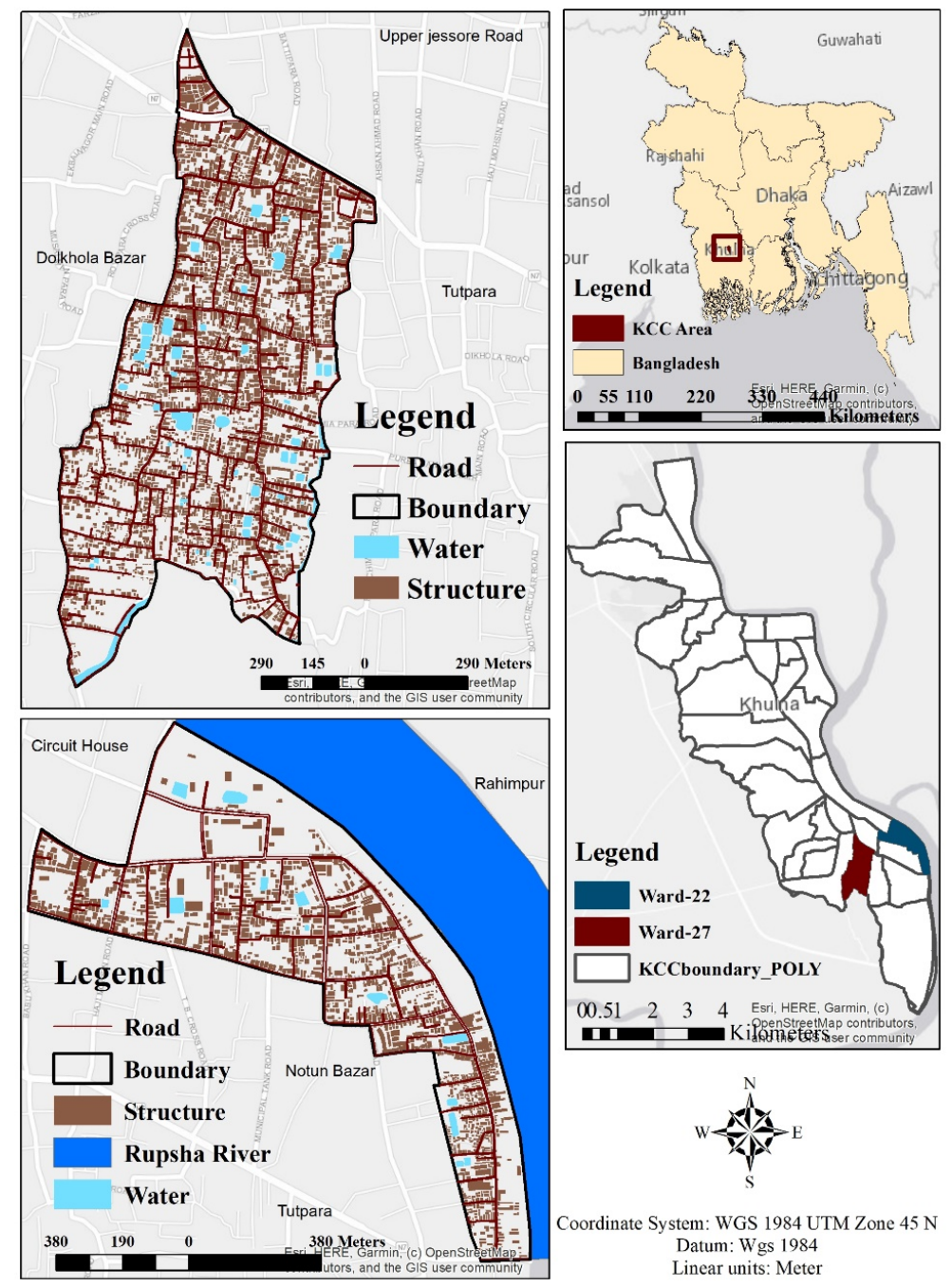

Figure 1. Study area map 
The survey data shows the population of ward-22 was 21633 and ward-27 was 31489 . The population density of the study area was too high where the standard population density in 25 per sq. $\mathrm{km}$. Ward-27 was substantially a residential area with dense housing and the construction of numerous new structures. In contrast, ward-22 was considered to be a commercial area with several factories, small industries, warehouses, government offices and administrative buildings [24]. 1 no custom ghat and forest ghat were located in this ward which provided river transportation service to the other side of the river. According to the survey data, ward-22 had dense greeneries compared to ward-27 (ward office, 2020). The state of the transportation system and vehicle circulation, as well as the adequacy of utility services, was reasonably acceptable, although the overall drainage and water supply system was not up to the mark.

\subsection{Land use land cover profile}

Land use classification is a system for identifying land cover and the types of human activity that take place on it [24-25]. It may also make the assessment of environmental impacts on land, as well as potential or alternative uses of land, easier. In the land use land cover profile section, this research evaluated land use land cover map, structure types over the study area, and structure uses for different purposes.

\subsection{LULC classification}

The spatial resolution of Landsat 8 (OLI 30m resolution) images was applied to analyze the Land use and Land Cover (LULC) types in ArcGIS 10.5 edition for the year 2020 [26-29]. Following the literature, the maximum likelihood supervised image classification method was used in this study to determine the land cover types [30-31]. To recognize the land cover design, the land cover type was classified into four categories (mixed land-use area, open land, water bodies, and vegetation) using the most intensive likelihood supervised classification method $[32,41]$. The assessment of shape, height and incline was designed to survey the geographical conditions of the chosen study region [33-34].

\subsection{Normalized difference vegetation index (NDVI)}

To detect the Normalized Difference Vegetation Index (NDVI), the Landsat Near-Infrared spectral band and Red spectral bands were used. In the red spectral band, the integration of radiation and the maximum impression of radiation in the near-infrared (NIR) spectral band was used to calculate the NDVI as shown in equation (1) [35-36].

$$
\text { NDVI }=(\text { NIR Band }- \text { Red Band }) /(\text { NIR Band }+ \text { Red Band })
$$

The NDVI was measured in real-time to determine the variation in land cover during the assessment time frame. In order to estimate the vegetation cover, NDVI had been used numerous times in previous investigations. The NDVI estimation ranges from -1.0 to +1.0 , however exceptionally low NDVI estimates (-0.1 and below) relating to infertile rock, sand, or urban centres and developed areas. The water cover is represented by zero. Moderate values indicated that the vegetation was thin ( 0.1 to 0.3 ), whilst high quality indicated that the vegetation was thick ( 0.6 to 0.8 ) $[37,42]$.

e-ISSN: $2289-7771$ 


\subsection{Normalized difference moisture index (NDMI)}

The NDMI technique was used to estimate the water content of vegetation. It was the ratio between the NIR and SWIR raster bands [31]. Here, NIR means Near-Infrared and SWIR means short weave Infra-Red [5]. The NDMI calculation is shown in equation (2).

$$
\mathrm{NDMI}=(\mathrm{NIR}-\mathrm{SWIR}) /(\mathrm{NIR}+\mathrm{SWIR})
$$

\subsection{Normalized difference buildup index (NDBI)}

The Normalized Difference Buildup Index (NDBI) represents the density of the built-up area on the land surface as a function of the ratio between the difference and the amount of near-infrared and shortwave infrared refracted radiation collected by the Landsat Multi-spectral sensor utilizing the conditions as expressed in equation (3)[31,33].

$$
\mathrm{NDBI}=(\mathrm{SWIR}-\mathrm{NIR}) /(\mathrm{SWIR}+\mathrm{NIR})
$$

The NDBI value ranges between -1 and 1 . The greater the value, the more developed land, metropolitan region, or constructed territory there is the lower the value, the less developed land, country region, or undeveloped territory $[30,36]$.

\subsection{Normalized difference salinity index (NDSI)}

Soil salinity is one of the detrimental environmental disasters, and Bangladesh is unquestionably one of the most affected countries [38]. Khulna city had been affected by soil salinity difficulties in the fields of agriculture, fish, shrimp, and cattle production, as well as built infrastructure, due to its geographical location in Bangladesh's coastal area [39]. The salinity data from Landsat photos was calculated using the Normalized Difference Salinity Index (NDSI) as demonstrated in equation (4) [38].

$$
\text { NDSI }=(\text { Red Band }- \text { NIR Band }) /(\text { Red Band }+ \text { NIR Band })
$$

The value of NDSI varies between -1 to +1 and the higher the value of NDSI, the higher the soil salinity [40].

\subsection{Land surface temperature (LST)}

LST is the soil surface's radioactive surface temperature, which plays an important role in the fundamental science of the land surface through the energy cycle and water trading with the environment $[33,26]$. The assessment of the LST from satellite thermal data included a number of methodologies, such as sensor radiometric alignment, the rectification of air and surface reflectivity, depiction of land-cover spatial variety, and so on. In this study, to address the current ecological condition of the study area, the LST of that particular area was resolved. The complexities of the cycle for inducing LST from Landsat images is as expressed in equation (5) [30-31].

$$
\mathrm{L} \lambda=\mathrm{AL}+\mathrm{ML} \times \mathrm{QCAL}
$$

Where, $\mathrm{L} \lambda$ is TOA spectral radiance $(\mathrm{W} /(\mathrm{m} 2 \times \mathrm{sr} \times \mu \mathrm{m}))$, ML is radiance multiplicative scaling factor for the band, AL is radiance additive scaling factor for the band, and QCAL is the quantized calibrated pixel value in Digital Numbers (DN). 
In the second step, the TOA spectral radiance ( $\mathrm{L} \lambda$ ) values were converted into another variable called At-Satellite Brightness Temperature (TB).

$$
\mathrm{TB}=\mathrm{K} 2 /(\ln (\mathrm{K} 1 / \mathrm{L} \lambda+1)
$$

Where, TB is at satellite brightness temperature, in Kelvin (K), and $\mathrm{K}$ and $\mathrm{K} 2$ are thermal conversion constants for the band. Finally, the TOA brightness temperature was converted to Land Surface Temperature (LST) values using the equation (7).

$$
\mathrm{LST}=[\mathrm{TB} /(1+(\lambda \times \mathrm{TB} / \alpha)) \times \ln \varepsilon]
$$

Where, LST is the land surface temperature in Kelvin $(\mathrm{K}), \lambda$ is the wavelength of emitted radiance, $\alpha$ is $\mathrm{hc} / \mathrm{k}(1.438 \times 10-2 \mathrm{mK}), \mathrm{h}$ is Planck constant $(6.626 \times 10-34 \mathrm{~J} \mathrm{~s}-1), \mathrm{c}$ is the velocity of light $(2.998 \times$ $108 \mathrm{~m} \mathrm{~s}-1), \mathrm{k}$ is Boltzmann constant $(1.38 \times 10-23 \mathrm{~J} \mathrm{~K}-1)$, and $\varepsilon$ is the surface emissivity which is calculated according to equation (8).

$$
\varepsilon=(0.004 \times \mathrm{Pv})+0.986
$$

Where, $\mathrm{Pv}$ is the vegetation proportion calculated using equation (9).

$$
\mathrm{Pv}=\left[(\text { NDVI - NDVImin) } /(\text { NDVI -NDVImax })]^{2}\right.
$$

To obtain land surface temperature values in degrees Celsius $\left({ }^{\circ} \mathrm{C}\right), 273.15$ was subtracted from the underlying characteristics (K). Because LST has an impact on the environment and causes unusual weather changes, the weighted overlay technique considers greater LST estimations to be danger zones.

\subsection{Methodological framework}

The methodological framework describes the methodological process and overview of the whole study (Figure 2).

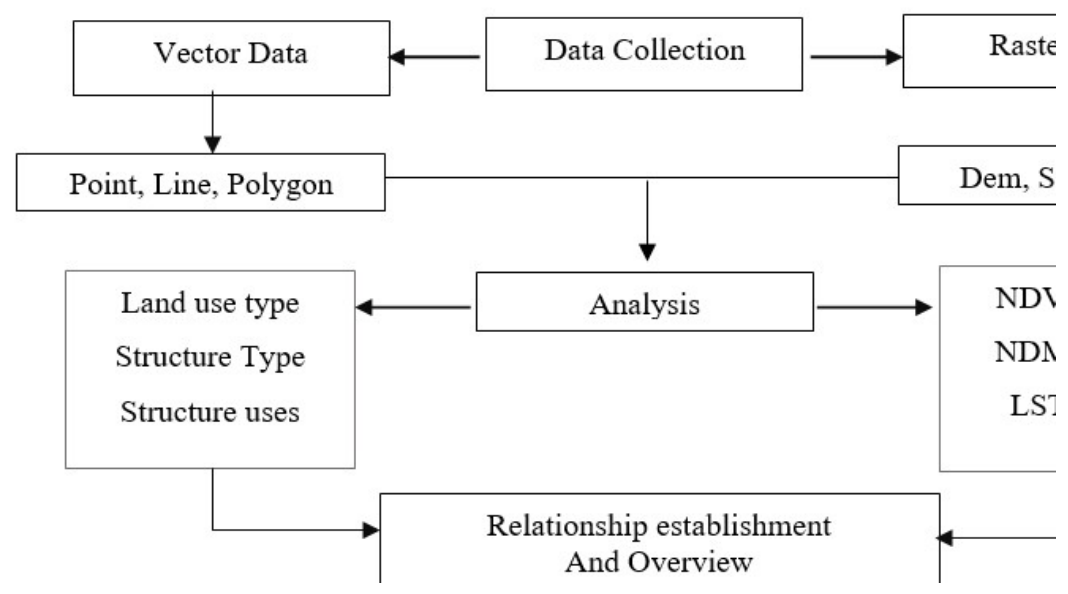

Figure 2. Methodological Framework 


\section{Results and discussion}

\subsection{Land use land cover}
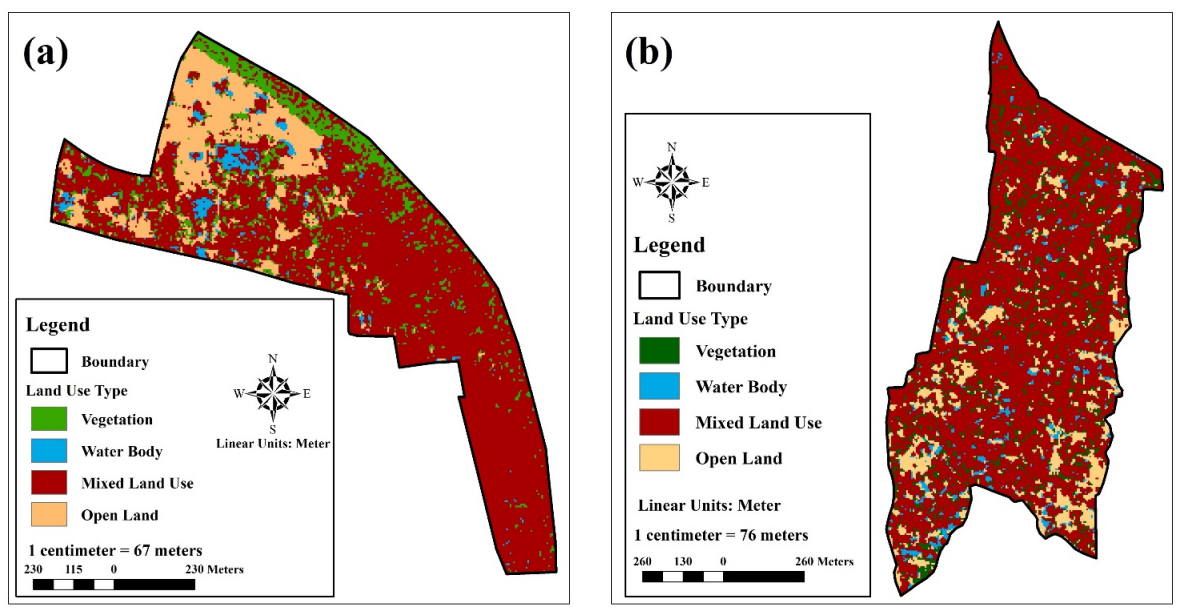

Figure 3. Land use land cover (a) ward-22, (b) ward-27.

Table 1. Land use land cover classes

\begin{tabular}{ccccc}
\hline LULC Type & \multicolumn{2}{c}{ Ward-22 } & \multicolumn{2}{c}{ Ward-27 } \\
\hline & Area percentage & Area in acre & Area percentage & Area in acre \\
\hline Build up & 59 & 99.29759 & 71.5 & 147.4759 \\
Open Space & 20.5 & 34.50171 & 13 & 26.8138 \\
Vegetation & 13.5 & 22.72064 & 8 & 16.5008 \\
Water body & 7 & 11.78107 & 7.5 & 15.4695 \\
Total & $\mathbf{1 0 0}$ & $\mathbf{1 6 8 . 3 0 1}$ & $\mathbf{1 0 0}$ & $\mathbf{2 0 6 . 2 6}$ \\
\hline
\end{tabular}

Ward-22 covered an area of 168 acres. From the LULC classification, most of ward 22 was a built-up area (Figure 3(a)). Almost 59\% (99.29 acres) of the area was a built-up area where 20.5\%, $13.5 \%$ and $7 \%$ of the area were open space, vegetation and water body accordingly. On the other hand, $71.5 \%$ (around 147.47 acres) of the area was a built-up area in ward-27 (Figure 3(b)). The results also showed that ward-27 contained an area of 16.50 acres of vegetation which was only $8 \%$ of the total area (Table 1).

\subsection{Land use pattern}

\subsubsection{Structure pattern in ward-22}

The structure type of ward-22 showed only $9.5 \%$ of the structures are katcha (Figure 4(a)). These structures were made of wood, bamboo, straw and hay. The maximum of the structures is pucca featuring high rise buildings, concrete structures (63.32\%). The west side of the ward consisted of most of the structures and was considered a residential area (Figure 4(b)). Only $27.18 \%$ of the structures were semi-pucca type. These included small shops with tin shades and concrete walls. Houses in slums were semi-pucca structures. 

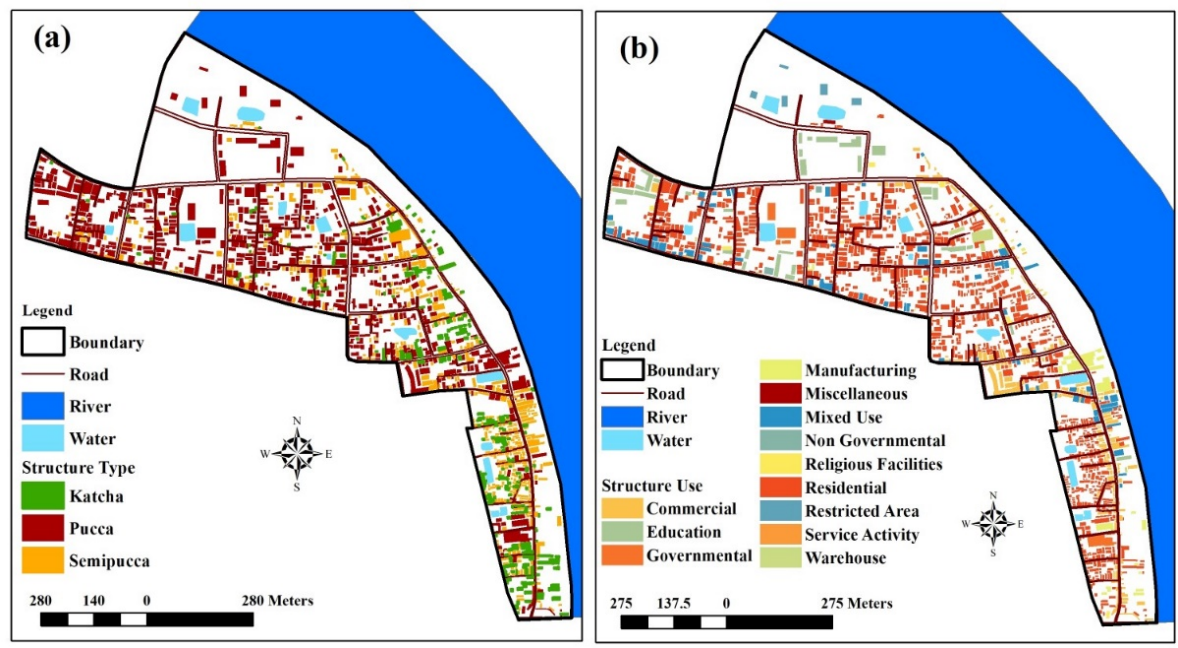

Figure 4. Ward-22 (a) Structure type, (b) Structure use pattern.

Table 2. Structure use pattern of ward-22

\begin{tabular}{ccc}
\hline Land Use type (ward-22) & Area in acre & Percentage \\
\hline Commercial Activity & 20.7346832 & 12.32 \\
Education and Research & 13.2284586 & 7.86 \\
Governmental Services & 5.6885738 & 3.38 \\
Manufacturing and Processing Activity & 7.0518119 & 4.19 \\
Miscellaneous & 0.504903 & 0.3 \\
Mixed-Use & 15.0292793 & 8.93 \\
Non-Governmental Services & 0.7405244 & 0.44 \\
Religious Facilities & 1.7166702 & 1.02 \\
Residential & 98.7085365 & 58.65 \\
Restricted Area & 2.0869324 & 1.24 \\
Service Activity & 0.3197719 & 0.19 \\
Warehouse & 2.4908548 & 1.48 \\
Total & 168.301 & 100 \\
\hline
\end{tabular}

In terms of structure use, almost $59 \%$ of the total structures were residential buildings (Table 2). $12 \%$ of the structures were used for commercial activity. These included shops, bazaars, small factories, industries, offices, etc. $8.93 \%$ of the area referred to as mixed-use types which included residential buildings with commercial purposes or industrial use mixed with residential land use types. Governmental and non-governmental services covered almost $4 \%$ of the study area which consisted of the district court, police station, development authorities and so on. Educational institutions such as primary and secondary schools, government colleges, and research institutes covered $7.86 \%$ of the land use (Table 2).

\subsubsection{Structure pattern in ward-27}

Ward-27 had $65.32 \%$ of pucca housing (Figure 5(a)). From the field survey data, it was witnessed that numerous constructions of new apartments and housing were going on. The katcha structures covered $11 \%$ of the total structures. $13.70 \%$ of the structures were semi-pucca type. Ward- 
27 had several slums clustered around the ward. The structures in slums were generally made of concrete floors with bamboo and tin shade roofing.

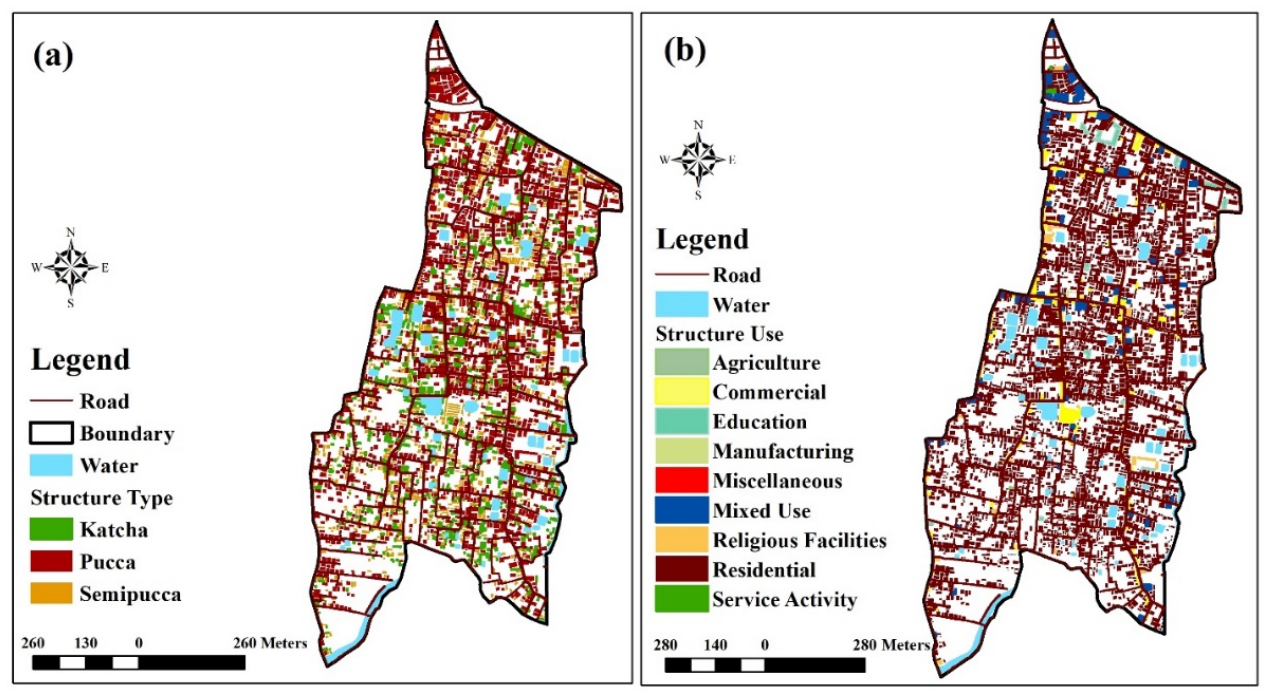

Figure 5. Ward-27 (a) Structure type, (b) Structure use pattern.

Table 3. Structure use pattern of ward-27

\begin{tabular}{ccc}
\hline Land Use type (ward-27) & Area in acre & Percentage \\
\hline Agriculture & 0.0598154 & 0.029 \\
Commercial Activity & 13.035632 & 6.32 \\
Education and Research & 1.258186 & 0.61 \\
Manufacturing and Processing Activity & 0.288764 & 0.14 \\
Miscellaneous & 0.474398 & 0.23 \\
Mixed-Use & 5.816532 & 2.82 \\
Religious Facilities & 1.670706 & 0.81 \\
Residential & 183.323888 & 88.88 \\
Service Activity & 0.1794462 & 0.087 \\
Blank & 0.1526324 & 0.074 \\
Total & 206.26 & 100 \\
\hline
\end{tabular}

Predominantly, Ward-27 was considered to be a residential area with almost $89 \%$ of the total land use type used for residential purposes (Table 3), which was $30 \%$ more compared to ward-22. Among other land-use types, commercial purposes only covered $6.32 \%$ of the total land-use type. This study showed how densely populated ward- 27 became due to the unplanned construction of residential buildings without following building codes. In other land use types, $2.82 \%$ of the area had mixed-use purposes. This referred to a residential building with shops, a mix of commercial, industrial and residential land use types (Figure 5(b)). 


\subsection{Land surface components of ward-22}
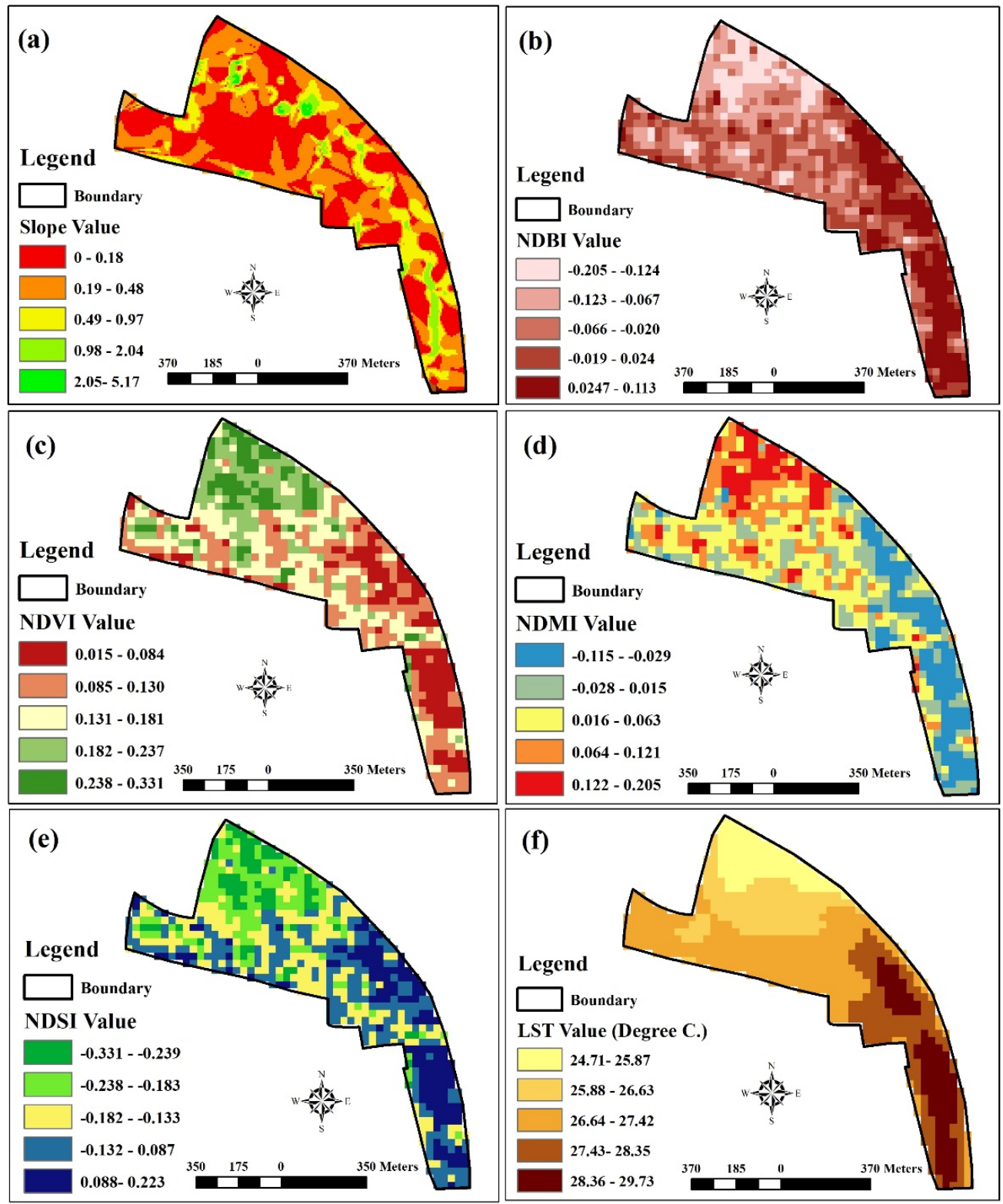

Figure 6. Maps of Ward-22 (a) Slope, (b) NDBI, (c) NDVI, (d) NDMI, (e) NDSI, (f) LST.

Ward-22 had a considerably very low slope (Figure 6(a)). The maximum area had a slope ranging from 0 to 0.08 and in some places, the slope ranged from 0.19 to 0.48 . The southern part of the ward had a comparatively higher slope (0.98 to 5.17) compared to other parts of the area.

Higher values (-0.019 to 0.113) of the Normalized Difference Buildup Index (NDBI) were observed in the southeast part of ward-22 (Figure 6(b)). The high values indicated more structures, built-up area, and more development, which also meant more risk and vulnerability towards disasters. A lower value was seen in the northern part where the amount of structure was relatively low. 
As moderate values of NDVI (0.1 to 0.3$)$ represented a thin vegetation layer, the whole ward fell into the moderate vegetation category, among which the northwest part of the ward had higher values of NDVI than the rest of the study area. The southeast part showed very poor vegetation cover ranging from 0.015 to 0.130 (Figure 6C).

NDMI referred to the water content in vegetation and from Figure 6(d) it is clear the NDMI values were higher where NDVI values were higher. The northeast part of the ward showed higher values of NDMI. In this area, vegetation was dense so the moisture content was high, whereas the southeast part had lower NDMI values $(0.064$ to 0.121$)$. The areas in the west showed moderate values of NDMI where vegetation density and built-up area were balanced.

Figure 6(e) shows the NDSI values of ward-22. The NDSI values increased when intense salinity was present in the soil. The southeast side of the ward was adjacent to the Bhairab river, so naturally, the soil in this area was more saline (-0.132 to 0.223$)$ compared to the rest of the area due to river salinity. On the other hand, moderate $(-0.182$ to -0.133$)$ and lower values $(-0.331$ to -0.183$)$ of NDSI were observed in the upper parts of the area.

Greater values of LST (27.43 to 29.73) were seen in the southeast part of ward-22 which indicated higher surface temperature and greater risk (Figure 6(f)). The vegetation density was thinner in this part of the area. As a result, the land absorbed most of the heat increases the surface temperature. It also indicated a densely built-up area sustaining more heat.

\subsubsection{Evaluation of relationships among surface components (ward-22)}

Figure 7 represents the correlation between different land surface dynamics. The higher positive $\mathrm{R}$ square values represented a positive significant correlation between the land surface indices and the negative or downward trend of correlation and negative $\mathrm{R}$ square values also provided a negative significant relationship. Figure 7 (a) shows a negative relationship between NDVI and NDBI where the R square value was 0.57 . Figure 7 (b) provides an insight into the association between NDMI and NDBI where the R square value was 0.58 . Figures 7 (a) and 7(b) show negative trends which meant if the built-up index increased, the NDVI value decreased in the study area. Figure 7(c) provides a highly positive correlation ( $\mathrm{R}$ square $=0.72$ ) between NDVI and NDMI which meant as the amount of vegetation increased, the amount of moisture increased.

Figure 7 (d, e and $\mathrm{f}$ ) shows the relationship between NDSI with respect to NDBI, NDVI and NDMI. There was no significant relationship observed as the $\mathrm{R}$ square value was observed 0.079 , 0.018 and 0.032 (negative trend line but very low R square close to zero) accordingly.

On the other hand, Figure 7 (g) shows that there was a highly positive correlation between LST and NDBI showing an R square value of 0.77 , which meant land surface temperature increased with the increase of built-up area. Figure 7 (h) and Figure (i) reveal the R square values 0.36 and 0.42 accordingly showing a negative trend line. According to Figure 7(h) and Figure 7 (i), it is clear that there was a somewhat negative relation between LST with respect to NDVI and NDMI. The negative trend/relation meant if the amount of LST increased, the amount of NDVI and NDMI decreased.

\subsection{Land surface components of ward-27}

From the slope map (Figure 8 a), it is visible that most of the area lay in the lower slope area. The slope values ranged from 0.00 to 0.15 which was very low. Only a small area of the southwest portion of ward-27 was identified as a relatively higher slop area which ranged from 0.82 to 3.54 .

NDBI values ranged from -0.199 to 0.078 (Figure $8 \mathrm{~b}$ ). Lower NDBI values were observed in the southeast and southwest parts of ward-27. NDBI values varied from -0.064 to 0.078 mostly in ward-27 whereas NDVI provided a completely different scenario.

e-ISSN: $2289-7771$ 
As ward-27 was mostly built up the amount of vegetation was very low (Figure $8 \mathrm{c}$ ). Most of the wards, specifically the northeast and northwest portions, showed lower values of NDVI (0.027 to 0.144). The core area represented very low values of NDVI. On the other hand, the southeast and southwest parts of the ward showed moderate to high values of NDVI (0.145 to 0.364). This represented moderately high vegetation density.
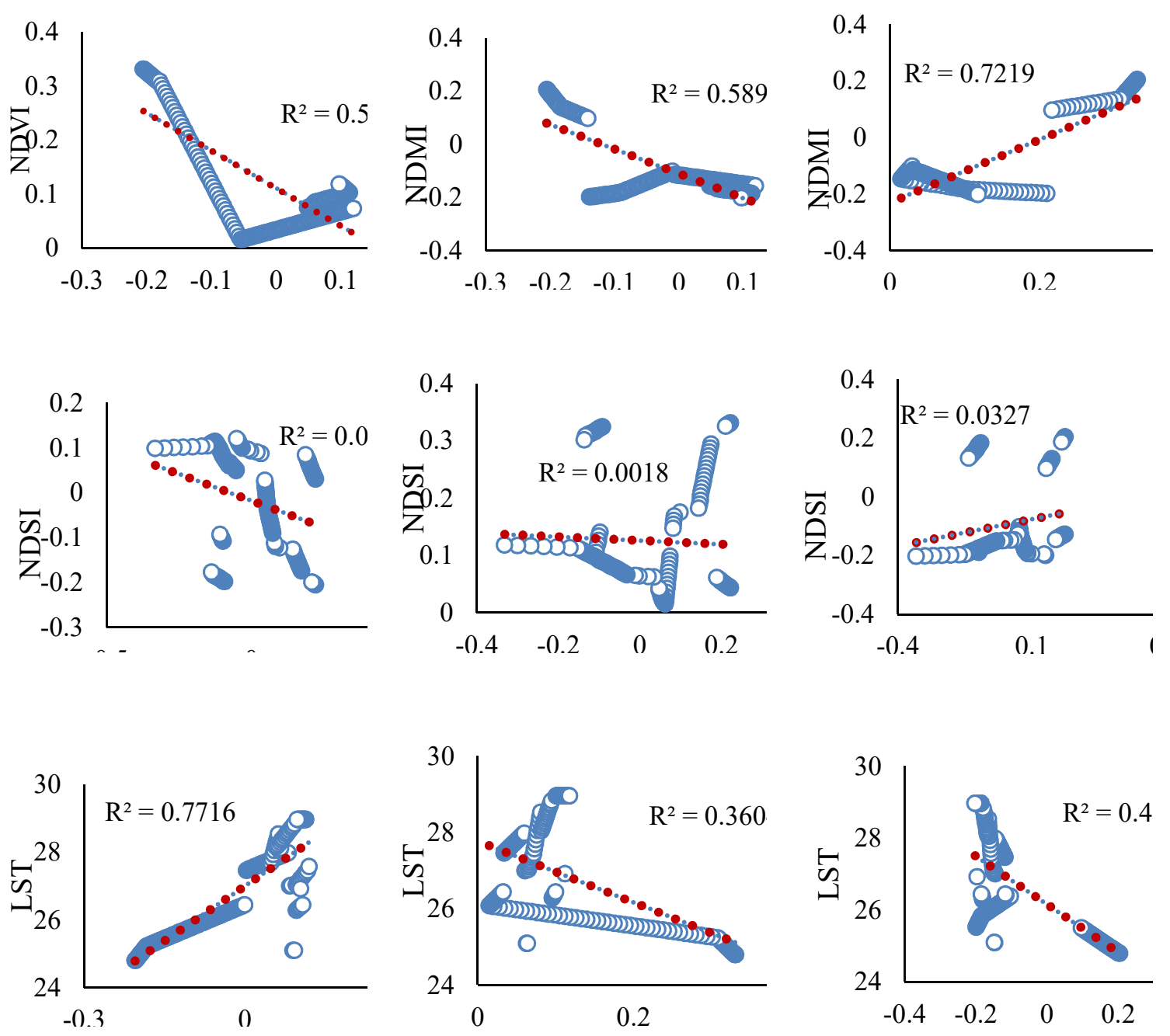

Figure 7. Relationship among Satellite-based Indexes of ward-22 (a) NDVI with respect to NDBI, (b) NDMI with respect to NDBI, (c) NDMI with respect to NDVI, (d) NDSI with respect to NDBI, (e) NDSI with respect to NDVI, (f) NDSI with respect to NDMI, (g) LST with respect to NDBI, (h) LST with respect to NDVI, (i) LST with respect to NDMI. 


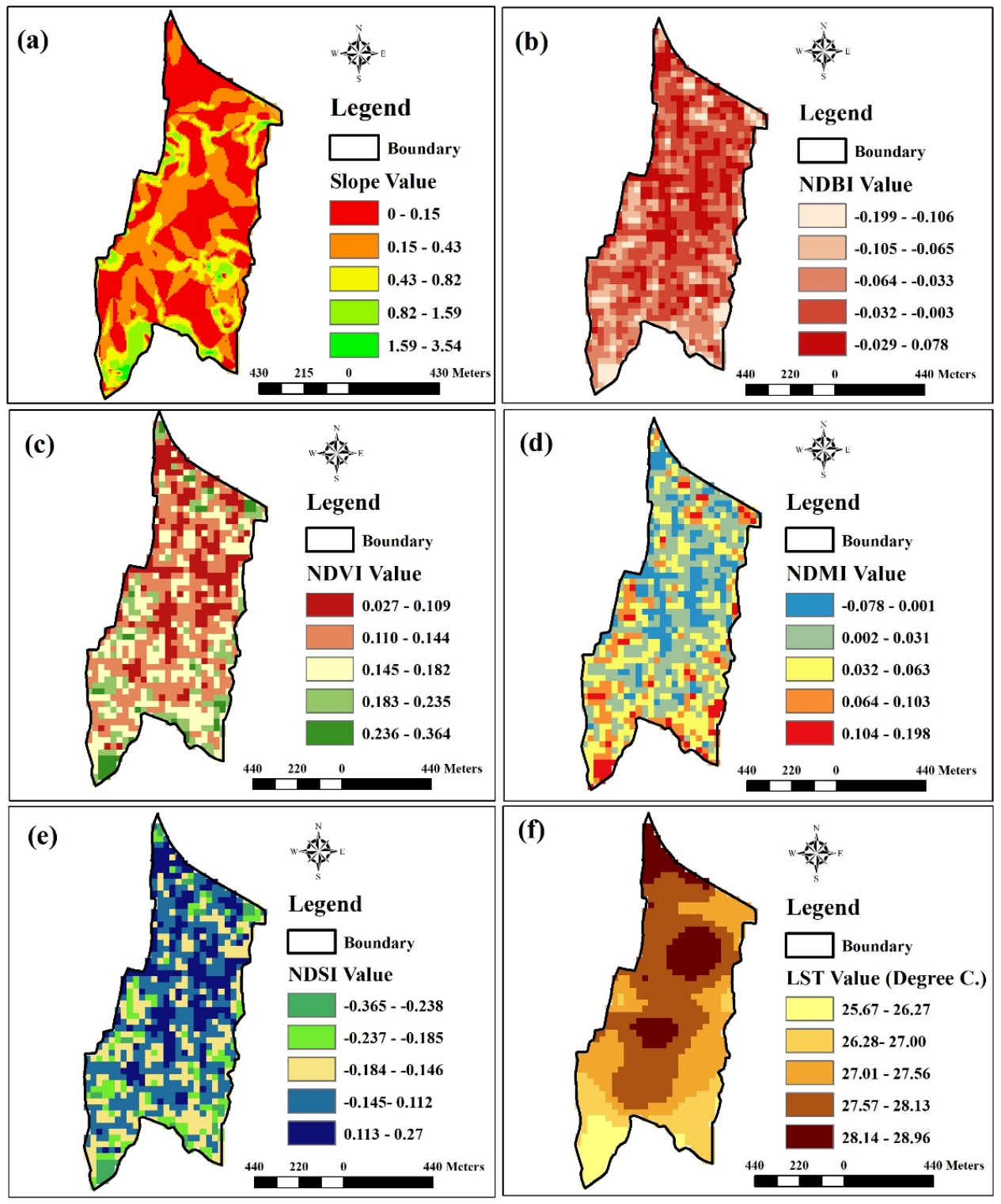

Figure 8. Maps of Ward-27 (a) Slope, (b) NDBI, (c) NDVI, (d) NDMI, (e) NDSI, (f) LST.

NDMI and NDVI had positive relation. Similar to NDVI, NDMI values were higher in the southeast and southwest parts of the study area (0.064 to 0.198). On the contrary, NDMI values were observed to be moderate ( 0.032 to 0.063$)$ to low ( -0.078 to 0.031$)$ in the core area to the northern portion of the study area (Figure $8 \mathrm{~d}$ ).

Figure 8 (e) illustrates the Normalized Difference Salinity Index. The values of NDSI were high in the north part of the ward ( 0.113 to 0.27$)$. In the core area, the values were observed to be moderate from -0.184 to -0.146 . On the contrary, the southern portion showed less salinity $(-0.365$ to -0.185$)$ due to the presence of dense vegetation and less structure.

LST increased where there was less vegetation and more buildup area. The northern part of the area had comparatively less vegetation so the surface area absorbed more heat causing excessive 
temperature rise (Figure $8 \mathrm{f}$ ). The core area had moderate to low values of LST (28.13 to 27.56). The southeast and southwest parts of the study area had low to very low values of LST (25.67 TO 27.00).

\subsubsection{Evaluation of relationships among surface components (ward-27)}
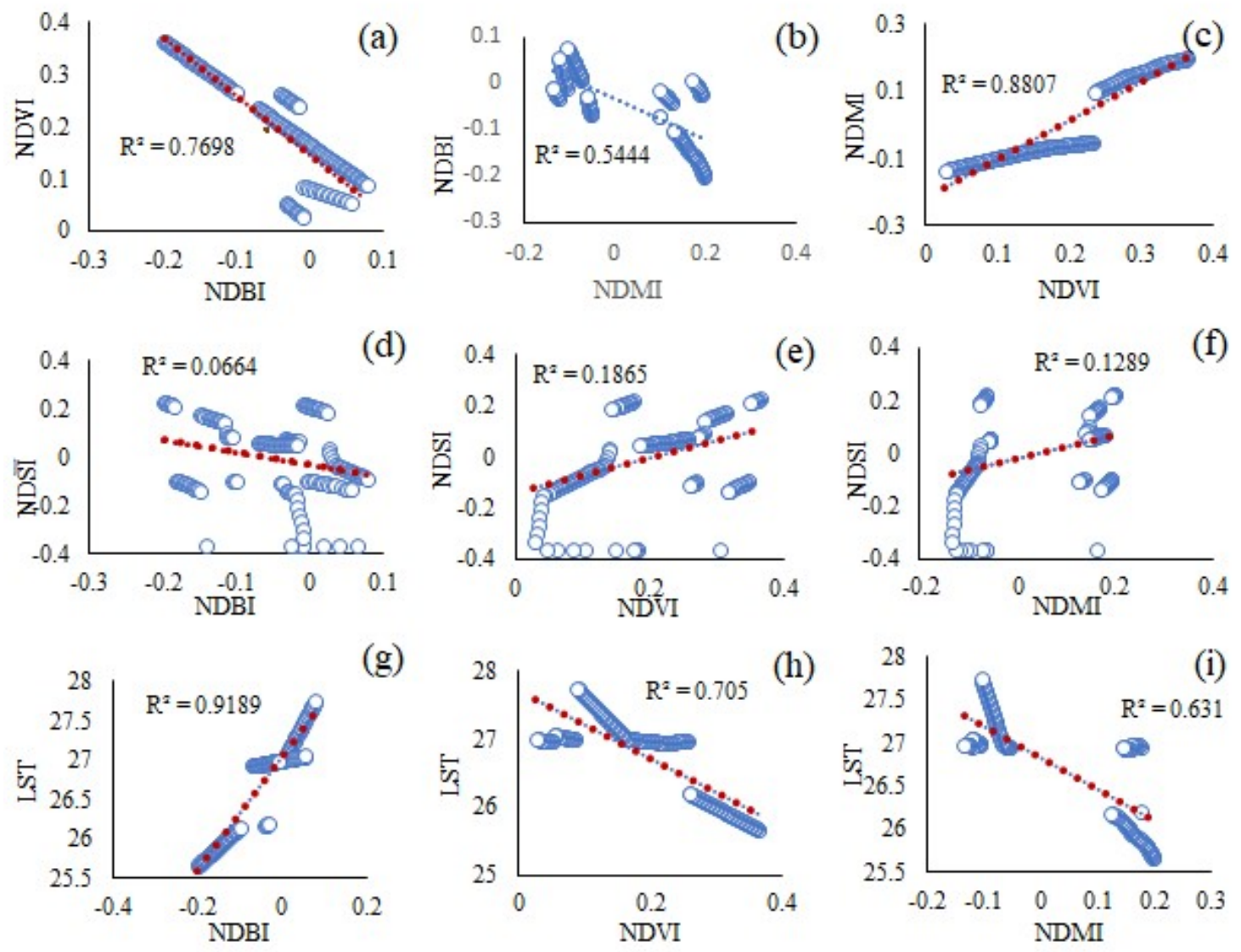

(g)
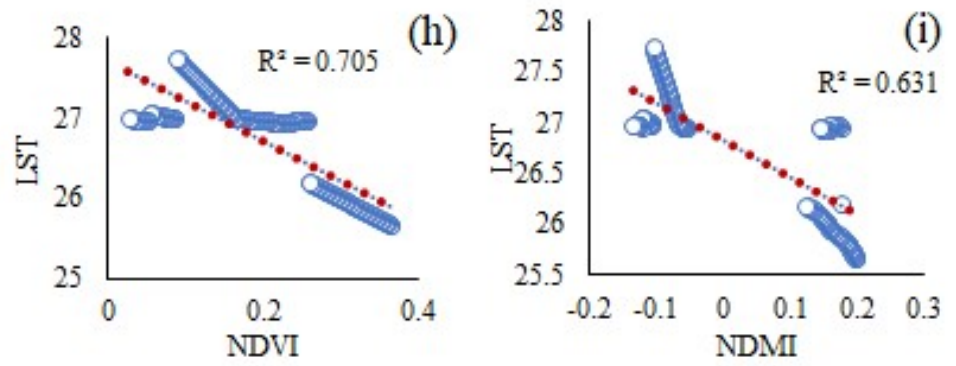

Figure 9. Relationship among Satellite-based Indexes of ward-27 (a) NDVI with respect to NDBI, (b) NDMI with respect to NDBI, (c) NDMI with respect to NDVI, (d) NDSI with respect to NDBI, (e) NDSI with respect to NDVI, (f) NDSI with respect to NDMI, (g) LST with respect to NDBI, (h) LST with respect to NDVI, (i) LST with respect to NDMI.

Figure 9 shows the relationship between various land surface dynamics. Figure 9 (a) depicts a negative relationship between NDVI and NDBI, with an R square of 0.76 . Figure 9 (b) shows the negative relationship between NDMI and NDBI, with an R square value of 0.54 . Figure 9 (c) shows a strong positive correlation between NDVI and NDMI (R square $=0.88$ ). This meant that as the amount of vegetation grew, so did the amount of moisture.

The relationship between NDSI and NDBI, NDVI, and NDMI is shown in Figure 9 (d, e, and f). The $\mathrm{R}$ square values were $0.066,0.018$, and 0.012 (very low $\mathrm{R}$ square value close to zero) respectively, indicating that there was no meaningful correlation. 
Figure 9(g), on the other hand, shows a strong positive correlation between LST and NDBI, with an $\mathrm{R}$ square value of 0.91 , indicating that land surface temperature rose as the built-up area increased. Figure $9(\mathrm{~h})$ and (i) show R square values of 0.70 and 0.63 , respectively. There was a clear negative trend of LST with respect to NDVI and NDMI, as shown in Figures 9(h) and 9(i). The negative trend/relation meant if the amount of LST increased, the amount of NDVI and NDMI decreased.

\section{Conclusion}

The study focused on evaluating the changes in land surface features and assessing the land use land cover profile for a smaller urban unit. In ward-22, almost $59 \%$ of the land, or 99.29 acres, were developed, with $20.5 \%, 13.5 \%$, and $7 \%$ of the land dedicated to open space, vegetation, and water bodies, respectively. On the other hand, $71.5 \%$ of the land was developed, totalling 147.47 acres. This indicated that a large area in ward-27 was being developed. Ward-22 and 27 had $63.32 \%$ and $65 \%$ pucca structures, respectively. The correlation pattern revealed a negative correlation between NDVI and NDBI showing $\mathrm{R}$ square value (negative trend) 0.57 and 0.76 for ward-22 and ward-27 accordingly. NDVI and LST also had a negative correlation where R square value was observed 0.36 for Ward-22 and 0.70 for Ward-27. On the other hand, NDMI and NDVI showed a positive correlation. Besides a highly positive correlation was observed between NDBI and LST for both ward-22 and ward-27.

The first objective of the research was completed by assessing NDBI, NDVI, NDMI, NDSI, Slope and LST. Ward-22 and ward-27 both lay in lower slope areas mostly. Both ward-22 and ward27 had lower slopes, less vegetation, less moisture, severe salinity, densely built-up areas, and a high land surface temperature. The second objective of the research was met by assessing the correlations among different land cover indices. To control the negative trend of NDVI and NDBI, the existing vegetation should be retained. Besides, the built-up area produced the most LST and for this reason, a positive trend was observed between LST and NDBI; where NDVI revealed a negative trend with respect to LST. The excessive amount of LST produced from the built-up area can be minimized by the enhancement of natural vegetation. Retention and enhancement of vegetation will also help to control the moisture of the microenvironment. The findings of the study may be useful to city planners and decision-makers in incorporating better urban management at the micro-level in response to reduce negative environmental effects.

\section{Acknowledgements}

The authors would like to thank the United States Geological Survey (USGS) from where we got the DEM data, Khulna City Corporation (KCC) and ward office of ward-22, 27 for providing valuable data to conduct this study.

\section{References}

[1] Jabbar, M. T., \& Zhou, X. (2011). Eco-environmental change detection by using remote sensing and GIS techniques: a case study Basrah province, south part of Iraq. Environmental Earth Science, 64, 1397-1407. DOI 10.1007/s12665-011-0964-5.

[2] Wang, H., Zhou, X., Zhou, X., Fu, H., Zhang, F., \& Ren, J. (2008). Eco-environmental degradation in the northeastern margin of the Qinghai-Tibetan Plateau and comprehensive ecological protection planning. Environ Geol, 55, 1135-1147. DOI 10.1007/s00254-007-1061-7. 
[3] Turner, R. K., van den Bergh, J. C., Söderqvist, T., Barendregt, A., Straaten, J. v., \& Maltby, E. (2000). Ecological-economic analysis of wetlands: scientificintegration for management and policy. Ecological Economics, 35, 7-23. https://doi.org/10.1016/S0921-8009(00)00164-6

[4] Naikoo, M. W., Rihan, M., Ishtiaque, M., \& Shahfahad. (2020). Analyses of land use land cover (LULC) change and built-up expansion in the suburb of a metropolitan city: Spatio-temporal analysis of Delhi NCR using landsat datasets. Journal of Urban Management, 9(3), 347-359. https://doi.org/10.1016/j.jum.2020.05.004.

[5] Rahaman, S., Kumar, P., Chen, R., Meadows, M. E., \& Singh, R. B. (2020). Remote Sensing Assessment of the Impact of Land Use and Land Cover Change on the Environment of Barddhaman District, West Bengal, India. Front. Environ. Sci, 8(127), 1-15. https://doi.org/10.3389/fenvs.2020.00127.

[6] Sharma, R., Chakraborty, A., \& Joshi, P. K. (2015). Geospatial quantification and analysis of environmental changes in urbanizing city of Kolkata (India). Environ Monit Assess, 87(4206), 1-12. DOI 10.1007/s10661-014-4206-7.

[7] Kalnay, E., \& Cai, M. (2003). Impact of urbanization and land-use change on climate. Nature, 423, 528531. https://doi.org/10.1038/nature01675

[8] Taubenböck, H., Wegmann, M., Roth, A., \& Mehl, H. (2009). Urbanization in India - Spatiotemporal analysis using remote sensing data . Computers Environment and Urban Systems, 33(3), 179-188. DOI:10.1016/j.compenvurbsys.2008.09.003.

[9] Grimm, N. B., Faeth, S. H., Golubiewski, N. E., Redman, C. L., Wu, J., Bai, X., \& Briggs, J. M. (2008). Global Change and the Ecology of Cities. Science, 319(5864), 756-760. http://dx.doi.org/10.1126/science.1150195.

[10] Taufik, A., \& Ahmad, S. S. (2016). Land cover classification of Landsat 8 satellite data based on Fuzzy Logic approach. Earth and Environmental Science, 37, 1-8. doi:10.1088/1755-1315/37/1/012062.

[11] Oliver, T. H., \& Morecroft, M. D. (2014). Interactions between climate change and land use change on biodiversity: attribution problems, risks, and opportunities. WIREs Climate Change, 5(3), 317-335. https://doi.org/10.1002/wcc.271.

[12] Baeza, S., \& Paruelo, J. M. (2020). Land Use/Land Cover Change (2000-2014) in the Rio de la Plata Grasslands: An Analysis Based on MODIS NDVI Time Series. Remote sensing, 12(3), https://doi.org/10.3390/rs12030381.

[13] Zhang, W., Zhu, Y., \& Jiang, J. (2016). Effect of the Urbanization of Wetlands on Microclimate: A Case Study of Xixi Wetland, Hangzhou, China. Sustainability, 8(9), 85.https://doi.org/10.3390/su8090885.

[14] Malik, M. S., Shukla, J. P., \& Mishra, S. (2019). Relationship of LST, NDBI and NDVI using Landsat-8 data in Kandaihimmat Watershed, Hoshangabad, India. Indian Journal of Geo Marine Sciences , 48(1), 2531.

[15] Julien, Y., \& Sobrino, J. A. (2009). The Yearly Land Cover Dynamics (YLCD) method: An analysis of global vegetation from NDVI and LST parameters. Remote Sensing of Environment, 113, 329-334. doi:10.1016/j.rse.2008.09.016.

[16] SZABÓ, S., GÁCSI, Z., \& BALÁZS, B. (2016). Specific Features Of Ndvi, NDWI And MNDWI As Reflected In Land Cover Categories. Landscape \& Environment, 10(3-4), 194-202. DOI: 10.21120/LE/10/3-4/13.

[17] Weng, Q., Lu, D., \& Liang, B. (2006). Urban Surface Biophysical Descriptors and Land Surface Temperature Variations. Photogrammetric Engineering \& Remote Sensing, 72(11), 1275-1286. https://doi.org/10.14358/PERS.72.11.1275

[18] Zhou, W., Huang, G., \& Cadenasso, M. (2011). Does spatial configuration matter? Understanding the effects of land cover pattern on land surface temperature in urban landscapes. Landscape and Urban Planning, 102(1), 54-63. DOI:10.1016/j.landurbplan.2011.03.009.

[19] JICA. (2012). Profile on Environmental and Social Considerations in Bangladesh. Dhaka, Bangladesh: JICA. 
[20] Agrawala, S., Ota, T., Ahmed, A. U., Smith, J., \& Aalst, M. v. (2003). Development and Climate Change in Bangladesh: Focus on Coastal Flooding and the Sundarbans. Paris, France: OECD.

[21] Haque, M. N., Siddika, S., Sresto, M. A., Saroar, M. M., \& Shabab, K. R. (2021). Geo-spatial Analysis for Flash Flood Susceptibility Mapping in the North-East Haor (Wetland) Region in Bangladesh. Earth Systems and Environment, 5, 365-384. https://doi.org/10.1007/s41748-021-00221-w .

[22] MFA. (2018). Climate Change Profile Bangladesh. Dhaka: Ministry of Foreign Affairs.

[23] Alam, M. S., \& Mondal, M. (2019). Assessment of sanitation service quality in urban slums of Khulna city based on SERVQUAL and AHP model: A case study of railway slum, Khulna, Bangladesh. Journal of Urban Management, 8(1), 20-27. https://doi.org/10.1016/j.jum.2018.08.002.

[24] Haque, M. N., Sresto, M. A., \& Siddika, S. (2021). Suitable Locations for Industrial Setup in Urban Context: Way Forward To Meet the SDGs for Khulna City, Bangladesh. International Journal of Built Environment and Sustainability, 8(2), 89-102. DOI: 10.11113/ ijbes.v8.n2.679.

[25] Haque, M. N., Siddika, S., \& Sresto, M. A. (2020). Nexus Between Urban Green Streets And The Sustainability: Case On Khulna City Corporation (Kcc) Area, Bangladesh. THE CREATIVITY GAME Theory and Practice of Spatial Planning, 8, 37-45. https://dx.doi.org/10.15292/IU-CG.2019.07.037-052.

[26] Ahmed, B., Kamruzzaman, M., Zhu , X., Rahman , M. S., \& Cho, K. (2013). Simulating Land Cover Changes and Their Impacts on Land Surface Temperature in Dhaka, Bangladesh. Remote Sensing, 5, 59695998. doi:10.3390/rs5115969.

[27] Al-Hanbali, A., Alsaaideh, B., \& Kondoh, A. (2011). Using GIS-Based Weighted Linear Combination Analysis and Remote Sensing Techniques to Select Optimum Solid Waste Disposal Sites within Mafraq City, Jordan. Journal of Geographic Information System, 3, 267-278.doi:10.4236/jgis.2011.34023.

[28] Stibig, H. J., Belward, A. S., Roy, P. S., Wasrin, R., Agarwal, S., Joshi, P. K., . . Giri, C. (2006). A landcover map for South and Southeast Asia derived from SPOT-VEGETATION data. Journal of Biogeography, 34(4), 625-637. https://doi.org/10.1111/j.1365-2699.2006.01637.x.

[29] $\mathrm{Xu}, \mathrm{H}$. (2006). Modification of normalised difference water index (NDWI) to enhance open water features in remotely sensed imagery. International Journal of Remote Sensing, 27(14), 3025-3033. https://doi.org/10.1080/01431160600589179.

[30] Kafy, A. -A., Faisal, A. A., Sikdar, S., \& Hasan, M. M. (2020). Impact of LULC Changes on LST in Rajshahi District of Bangladesh: A Remote Sensing Approach. Journal of Geographical Studies, 3(1), 1123. DOI: $10.21523 / \mathrm{gcj} 5.19030102$.

[31] Georgiana, G., \& Urițescu, B. (2019). Land Use/Land Cover changes dynamics and their effects on Surface Urban Heat Island in Bucharest, Romania. International Journal of Applied Earth Observation and Geoinformation, 80, 115-126. DOI:10.1016/j.jag.2019.03.009.

[32] Bishta, A. Z. (2018). Assessment of the reliability of supervised classifications of Landsat-7, ASTER, and SPOT-5 multispectral data in rock unit discriminations of Jabal Daf-Wadi Fatima area, Saudi Arabia. Arabian Journal of Geosciences, 11(755), 2-21. https://doi.org/10.1007/s12517-018-4093-2.

[33] Zhang, Y., Gao, J., Liu, L., Wang, Z., Ding, M., \& Yang, X. (2013). NDVI-based vegetation changes and their responses to climate change from 1982 to 2011: A case study in the Koshi River Basin in the middle Himalayas. Global and Planetary Change, 108, 139-148. https://doi.org/10.1016/j.gloplacha.2013.06.012.

[34] Pontius Jr , R. G., \& Millones , M. (2011). Death to Kappa: birth of quantity disagreement and allocation disagreement for accuracy assessment. International Journal of Remote Sensing, 32(15), 4407-4429. https://doi.org/10.1080/01431161.2011.552923.

[35] Yadav, K., \& Congalton, R. G. (2019). Accuracy Assessment of Global Food Security-Support Analysis Data (GFSAD) Cropland Extent Maps Produced at Three Different Spatial Resolutions. Remote Sensing, 11(6). DOI:10.3390/rs11060630630.

[36] Zhang, Y., Odeh, I., \& Han, C. (2009). Bi-temporal characterization of land surface temperature in relation to impervious surface area, NDVI and NDBI, using a sub-pixel image analysis. Int. J. Appl. Earth Obs. Geoinformation, 11, 256-264. DOI:10.1016/j.jag.2009.03.001. 
[37] Dash , P., Göttsche , F. M., Olesen , F. S., \& Fischer , H. (2002). Land surface temperature and emissivity estimation from passive sensor data: Theory and practice-current trends. International Journal of Remote Sensing, 23(13), 2563-2594. https://doi.org/10.1080/01431160110115041.

[38] Alam, M. Z., Boggs, L. C., Mitra, S., \& Haque, M. M. (2017). Effect of Salinity Intrusion on Food Crops, Livestock, and Fish Species at Kalapara Coastal Belt in Bangladesh. Journal of Food Quality, 1-23. https://doi.org/10.1155/2017/2045157.

[39] Azabdaftari , A., \& Sunar, F. (2016). Soil Salinity Mapping Using Multitemporal Landsat Data. Soil Salinity Mapping Using Multitemporal Landsat Data. The International Archives of the Photogrammetry, Remote Sensing and Spatial Information Sciences, Volume XLI-B7, 1-7. doi:10.5194/isprsarchives-XLIB7-3-2016.

[40] Khan, N. M., Rastoskuev, V. V., Shalina, E. V., \& Sato, Y. (2001). Mapping Salt-affected Soils Using Remote Sensing Indicators- A Simple Approach with the Use of GIS IDRISI. 22nd Asian Conference on Remote Sensing, 2001. Singapore: National University of Singapore.

[41] Sresto, M.A., Siddika, S., Haque, M.N. et al. (2021). Groundwater vulnerability assessment in Khulna district of Bangladesh by integrating fuzzy algorithm and DRASTIC (DRASTIC-L) model. Model. Earth Syst. Environ. https://doi.org/10.1007/s40808-021-01270-w.

[42] Sresto, M.A., Siddika, S., Haque, M.N., \& Saroar, M. (2021). Application of fuzzy analytic hierarchy process and geospatial technology to identify groundwater potential zones in north-west region of Bangladesh. Environmental Challenges, https://doi.org/10.1016/j.envc.2021.100214. 